\title{
Study on Relationship between Cultural Intelligence Level and Academic Self- Efficacy of Undergrads
}

\author{
Mustafa Vural ${ }^{1}$ \\ Alper Tunga Peker ${ }^{2}$
}

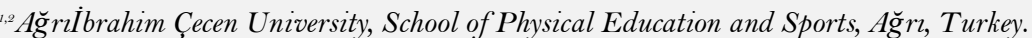

'Email: mustafaavurall@gmail.com Tel: +905352585512

'Email: tungapeker@hotmail.comTel:+905452429542

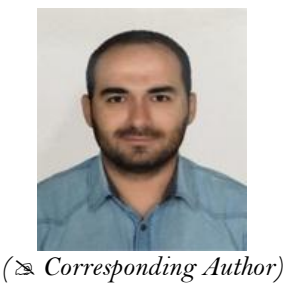

\section{Abstract}

Aim of this study is to determine the relationship between cultural intelligence and academic selfefficacy of undergrads, in terms of different variables. A total of 169 people, (101 male/ 68 female) participated in the research. "Cultural Intelligence Scale" and "Academic Self-Efficacy Scale" were used in the research. Mann-Whitney $U$ test was used for paired comparisons and Kruskal Wallis $\mathrm{H}$ test was used for multiple comparisons in the statistical analysis. Spearman correlation test was utilized to determine relationship between the scales. As a result of the research, it was determined that there were significant differences according to department of education and year of education variable and there were not significant differences according to other variables that are gender, place of accommodation and status of being interested in sports. When the relationship between academic self-efficacy and cultural intelligence was examined, it was concluded that there was a significant and positive relationship below the medium level.

Keywords: Cultural intelligence, Academic, Self-efficacy, Student, Sports, Undergrads, Training and Education.

Citation | Mustafa Vural; Alper Tunga Peker (2019). Study on Relationship between Cultural Intelligence Level and Academic Self-Efficacy of Undergrads. Asian Journal of Education and Training, 5(2): 335-342.

History:

Received: 4. February 2019

Revised: 15 March 2019

Accepted: 22 April 2019

Published: 11 June 2019

Licensed: This work is licensed under a Creative Commons

Attribution 3.0 License (cc) E.

Publisher: Asian Online Journal Publishing Group
Contribution/Acknowledgement: Both authors contributed to the conception and design of the study.

Funding: This study received no specific financial support.

Competing Interests: The authors declare that they have no conflict of interests.

Transparency: The authors confirm that the manuscript is an honest, accurate, and transparent account of the study was reported; that no vital features of the study have been omitted; and that any discrepancies from the study as planned have been explained.

Ethical: This study follows all ethical practices during writing.

\section{Contents}

1. Introduction

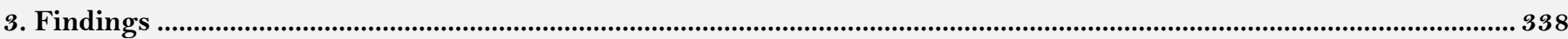

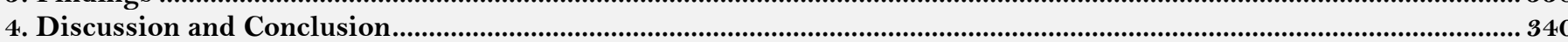

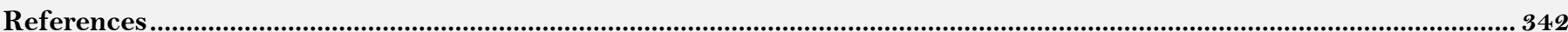




\section{Introduction}

It is thought that different opinions and cultures affect success and changes in societies in changing and developing world. Individuals with different cultures are also affected by each other and communicate differently. Intercultural communication and interaction will help societies to progress successfully.

Behavior acquired and passed from generation to generation is defined as culture. Culture is a sum of beliefs, values, behaviors that are learned and shared and their characteristics and symbols. In society, individuals may behave similarly. Learning, integrity and sharing subjects are important in terms of making culture clearer (Aman, 2012). Factors constituting culture may consist of material and moral elements. All kinds of materials and methods that meet basic needs of individuals in the society and in their harmony and struggle with life and nature, form material part of the culture (Eroğlu, 2007). Those that are visible such as dressing styles, architectures, roads, tools and equipment, constitute material elements. While material culture sums in societies indicate economic and technological development, it is also used for comparing countries. Moral part of culture is important in terms of perceiving social environment in the society. It is related to issues about how life has been organized from past to present and gives importance to transferring values such as traditions, marriages, relationships with relatives, religion and art to the next generations as well as politics, laws, education and economic systems (Wu, 2012).

Cultural differences began to gain importance and became popular in international area after $1960 \mathrm{~s}$ (Ng and Earley, 2006).From this point of view, after cultural values came into prominence, "cultural intelligence" concept that highlights being aware of differences between culturally different individuals, accepting differences and giving importance to differences, emerged (Yeşil, 2009) and it became strategically important to manage cultural differences. Cultural intelligence is defined as "being skilled and flexible about understanding cultures better, being in touch with people from other cultures, learning more about it and at the same time, understanding views and thoughts of individuals with different cultures, changing our negative thoughts about them in time" (Thomas and Inkson, 2004). Cultural intelligence is a skill and ability that creates an environment allowing a person from another country and from another society to interpret actions by gestures that are unfamiliar to such person (Gibson and Dibble, 2008). In another definition, cultural intelligence is defined as an individual's ability to understand, evaluate and interpret the moves, behaviors, voice, mimics, manners and emphasis of people from different cultures as people from the same culture (Earley and Mosakowski, 2004). According to another definition, cultural intelligence is defined as ability to reveal and adopt abstract concepts in societies in a correct and understandable way and ability to solve problems (Ang et al., 2007). In addition to this, it has been seen that there are many factors affecting formation of cultural intelligence. It is emphasized that among those, social intelligence and emotional intelligence concepts are important in development of cultural intelligence. Interaction of people with different cultures has given self-efficacy and self-confidence issues prominence. When Erasmus activities in the universities are considered, it is seen that there is interaction with different countries and societies. It can be asserted that this interaction provides a change in students' academic success and affects success. From this point of view, academic success is an important issue for individuals to be more successful in their work life and examinations to be held later.

Self-efficacy, it is known that self-efficacy theory that has been started to be used in different fields in recent years, has important effects on human behavior. It is seen that self-efficacy concept is frequently used in relation to learning related to education and academic performance or it is used with other situations of the student. Selfefficacy is known as self-persuasion of people about their abilities and it indicates a willingness that increases motivation and enables people to cope with new and difficult tasks. Negatively, it can be said that it causes a person to leave work incomplete or decrease in a person's interest in the work (Jerusalem, 2002).

Self-efficacy is a concept that underlies self-awareness and social learning theories. It is the ability of a person to act willingly in the face of a situation that will occur by comparing what should do be done. These are the ways in which an individual can be successful in difficult situations. In other words, it is ability of a person to know and understand himself (Korkmaz, 2004).Self-efficacy is generally used for a special situation. For example, while a student who continues to study in first grade has a high self-efficacy to solve simple word problems, the same student may have a lower self-efficacy perception towards more difficult mathematical processes (Uzel, 2009).

Perceived academic self-efficiency is the belief that students have for leading themselves to academic success and creating a job-related career environment (Solberg et al., 1993; Zimmerman, 1995). After Bandura introduced self-efficacy concept, studies conducted have shown that self-efficacy is effective in academic life at all levels of educational process. Researchers have carried out many studies that reveal importance of high academic selfefficacy. In addition to this, many studies about the fact that self-efficacy belief increases academic success, have also been revealed (Schunk, 1981;1982; Bandura, 1997; Pajares, 1997). In their study they conducted in in Netherlands on undergraduate students with high-intelligence levels, Vrugt et al. (1997) revealed that self-efficacy had a significant effect on students' examination performances.In their research, Lent et al. (1984) state that students with high academic success levels have high examination scores. Therefore, academic self-efficacy is one of the important variables for predicting students' successes (Wood and Locke, 1987; House, 1992; Elias and Loomis, 2002). From this point of view, it was aimed to analyze cultural intelligence levels and academic self-efficacy of university students in terms of different demographic variables, and it was also tried to determine relationship between the two variables and academic self-efficacy perceptions of the students according to their cultural intelligence levels.

\section{Method}

\subsection{Research Model}

In the research, screening model which aims to describe attitudes, tendencies and opinions numerically or quantitatively by performing studies on a sample group chosen from a population, has been used (Creswell, 2013). This method can be identified as describing a situation in the past or present as it is. What is important in this method is to be able to define an event, individual or object as it is in its conditions and to observe it without 
changing the current situation (Karasar, 2012). In the research, survey technique which is frequently utilized in screening studies, has been used as data collection technique (Erkus, 2013).

\subsection{Population and Sample}

Population of the study consists of university students who continue their education in different departments of school of physical education and sports. Sample group in the research was determined by selecting students in the school coincidentally, i.e. randomly at the time when education continued. Sample group of the research consists of a total of 169 voluntary students, of whom 101 are male and 68 are female.

\subsection{Data Collection Tools}

\subsubsection{Cultural Intelligence Scale}

It was prepared by KZÖ Ang et al. (2007) to reveal cultural intelligence of individuals. There are 20 items in 7 point likert type scale. Scale consists of 4 sub-dimensions called Metacognition, Cognition, Motivation and Behavior. There are 4 items in the metacognition sub-dimension reflecting mental processes that they use to understand cultural knowledge they have and whether individuals have control over the cultural information they have. Example Item: "I am aware of my cultural knowledge that I use in intercultural interactions." There are 6 items in cognition sub-dimension reflecting individuals' knowledge about different cultures. Example Item: "I know religious beliefs and cultural values of other cultures." There are 5 items in motivation sub-dimension reflecting interest of individuals in interacting with people from different cultures and their self-efficacy belief about this subject. Example Item: "I enjoy interacting with people from different cultures." There are 5 items in behavior subdimension reflecting individuals' ability to exhibit appropriate verbal or non-verbal behaviors when they meet people having different cultural backgrounds. Example Item: "I can change my speaking speed depending on requirements of intercultural interaction.” Exploratory Factor Analysis (EFA) and Confirmatory Factor Analysis (CFA) were performed by Ang et al. (2007) in order to reveal construct validity of KZÖ. EFA was performed on data obtained from 576 students with a form consisting of 40 items. As a result of EFA, 20 items with low factor load were removed from the scale. After this process, 20 items with factor load value varying between .52 and .80 and structure with 4 factors corresponding to theoretical basis, were obtained. It was found that correlations varied between .21 and .45 . As a result of the item analysis, it was determined that corrected item total correlations of the items in the scale were between .47 and .71. Cronbach Alpha internal consistency coefficients were founded as follows; .72 for metacognition sub-dimension, .86 for cognition sub-dimension, .76 for motivation sub-dimension and .83 for behavior sub-dimension.

\subsubsection{Academic Self-Efficacy Scale}

Original scale which was developed by Jerusalem and Schwarzer (1981) and which includes one dimension, consists of 7 items which demonstrates a meaningful structure for academic self-efficacy. Items in the scale are in the form of, "4 Point Likert Type Scale" (completely agree, agree, slightly agree, completely disagree). Original scale was developed by applying to 68 medical faculty students and the Cronbach Alpha value of the scale was found as .87. Researchers tested validity of the scale by looking at its correlation with content, logic and physiologically-based variables. Correlations of Academic Self-Efficacy Scale with Self Esteem Scale and Performance Scale Fear were determined as .37 and -.49 respectively. Researchers stated that content of the scale was in compliance with the subject and other psychological features tested gave information for validity of the scale (Jerusalem and Schwarzer, 1981). Academic Self-Efficacy Scale was translated into Turkish, applied to 672 university students and its validity and reliability were determined. According to the analysis results, the number of items in the original scale which was 7, was preserved in Turkish scale. According to factor analysis results, it was determined that Turkish scale was one dimensional like the original scale. In the study carried out by Schwarzer and Jerusalem, it was determined that correlation of the scale with Self-Esteem Scale was .370 in validity analysis of the scale; it was .435 for the scale adapted to Turkish and that it supported the information about validity of the scale. Cronbach Alpha reliability value of the original scale was determined as .87. Cronbach Alpha reliability value of the Turkish scale was also determined as .79 (Yilmaz et al., 2007).

\subsection{Statistical Analysis}

SPSS 22.0 Windows program was used to analyze data obtained. While Cronbach Alpha internal consistency coefficients related to the sub-dimensions of cultural intelligence scale were found as metacognition $(, 815)$, cognition (,788), motivation (,850), behavior $(, 813)$ and $(, 908)$ for total scale respectively, it was found as $(, 764)$ for academic self-efficacy scale. Data obtained from the scales did not distribute normally and therefore, nonparametric analysis methods were used. While Mann Whitney U test was used to compare scale scores of the participants according to their gender, Kruskal Wallis $\mathrm{H}$ test was used to compare scale scores of them according to age group, department of education and year of education, place of accommodation and status of being interested in sports. Spearman Correlation analysis was used to examine relationship between cultural intelligence scale scores and academic self-efficacy scale scores. 


\section{Findings}

Table-1.Frequency and Percentage Distributions Regarding Demographic Information of Participants.

\begin{tabular}{|c|c|c|c|}
\hline Variables & Sub-variables & $\mathbf{f}$ & $\%$ \\
\hline \multirow{4}{*}{ Age group } & 19-20 years & 33 & 19,5 \\
\hline & 21-22 years & 75 & 44,4 \\
\hline & 23-24 years & 40 & 23,7 \\
\hline & $24+$ years & 21 & 12,4 \\
\hline \multirow{2}{*}{ Gender } & Female & 68 & 40,2 \\
\hline & Male & 101 & 59,8 \\
\hline \multirow{3}{*}{ Department } & Physical Education and Sports Teaching & 91 & 53,8 \\
\hline & Coaching Education & 44 & 26,0 \\
\hline & Sports Management & 34 & 20,1 \\
\hline \multirow{4}{*}{ Year } & 1st year & 58 & 34,3 \\
\hline & 2nd year & 27 & 16,0 \\
\hline & 3rd year & 57 & 33,7 \\
\hline & 4th year & 27 & 16,0 \\
\hline \multirow{3}{*}{$\begin{array}{c}\text { Place of } \\
\text { Accommodation }\end{array}$} & Dormitory & 69 & 40,8 \\
\hline & With family & 54 & 32,0 \\
\hline & Student house & 46 & 27,2 \\
\hline \multirow{3}{*}{$\begin{array}{l}\text { Level of being } \\
\text { interested in } \\
\text { sports }\end{array}$} & Amateur & 105 & 62,1 \\
\hline & Professional & 44 & 26,0 \\
\hline & Referee & 20 & 11,8 \\
\hline
\end{tabular}

As shown in Table 1, 19,5\% of the participants are in age group 19-20, 44,4\% are in age group $21-22,23,7 \%$ are in age group $23-24$ and $12,4 \%$ are in age group $24+$, and $40,2 \%$ of them are female, $59,8 \%$ are male. $53,8 \%$ of the participants study in department of physical education and sports teaching, $26 \%$ of them study in department of coaching education and $20,1 \%$ of them study in department of sports management, $34,3 \%$ of them are in their 1 st year, $16 \%$ are in 2 nd year, 33,7\% are in 3rd year and $16 \%$ are in 4 th year. While $40,8 \%$ of the participants accommodate in dormitory, $32 \%$ of them accommodate in their families' houses and $27,2 \%$ accommodate in student house. While $62,1 \%$ of the participants are interested in sports as an amateur, $26 \%$ are interested in sports professionally and $11,8 \%$ of them are interested in sports as a referee.

\begin{tabular}{l|c|c|c} 
Table-2.Descriptive Statistics Related to Cultural Intelligence Scale and Academic Self-Efficacy Scale Scores of the Participants. \\
\hline Sub-dimensions & $\mathbf{N}$ & $\mathbf{X}$ & Ss \\
\hline Metacognition & 169 & 15,54 & 3,514 \\
\hline Cognition & 169 & 18,91 & 4,782 \\
\hline Motivation & 169 & 19,01 & 4,636 \\
\hline Behavior & 169 & 18,08 & 4,244 \\
\hline Cultural Intelligence Total & 169 & 71,54 & 13,690 \\
\hline Academic Self-efficacy & 169 & 21,41 & 4,086 \\
\hline
\end{tabular}

As shown in Table 2, When table is examined, it is seen that participants get high scores in metacognition dimension of cultural intelligence scale, they get score above medium level, close to high level in motivation and behavior sub-dimensions, they get medium level score in cognition dimension, they get score above medium level in whole scale and they get medium level score in academic self-efficacy scale.

Table-3.Comparison of Cultural Intelligence Scale Sub-Dimension Scores and Academic Self-Efficacy Scale Scores of the Participants According to Age Groups.

\begin{tabular}{|c|c|c|c|c|c|c|c|c|}
\hline Sub-dimension & Age group & $\mathbf{N}$ & $\mathbf{X}$ & Ss & Mean rank & $x^{2}$ & $\mathbf{p}$ & $\begin{array}{c}\begin{array}{c}\text { Difference between } \\
\text { groups }\end{array} \\
\end{array}$ \\
\hline \multirow{4}{*}{ Metacognition } & 19-20 years & 33 & 15,18 & 3,618 & 81,21 & \multirow{4}{*}{2,952} & \multirow{4}{*}{,399 } & \multirow{4}{*}{-} \\
\hline & 21-22 years & 75 & 16,15 & 3,135 & 92,05 & & & \\
\hline & 23-24 years & 40 & 14,80 & 4,033 & 77,59 & & & \\
\hline & $24+$ years & 21 & 15,38 & 3,457 & 79,88 & & & \\
\hline \multirow{4}{*}{ Cognition } & 19-20 years & 33 & 17,61 & 3,937 & 70,59 & \multirow{4}{*}{6,381} & \multirow{4}{*}{,094 } & \multirow{4}{*}{-} \\
\hline & 21-22 years & 75 & 19,73 & 4,774 & 93,57 & & & \\
\hline & 23-24 years & 40 & 19,00 & 5,064 & 86,78 & & & \\
\hline & $24+$ years & 21 & 17,86 & 5,141 & 73,64 & & & \\
\hline \multirow{4}{*}{ Motivation } & 19-20 years & 33 & 18,39 & 4,730 & 77,91 & \multirow{4}{*}{2,104} & \multirow{4}{*}{, 551} & \multirow{4}{*}{ - } \\
\hline & 21-22 years & 75 & 19.49 & 4,323 & 89,62 & & & \\
\hline & 23-24 years & 40 & 18,53 & 4,701 & 79,53 & & & \\
\hline & $24+$ years & 21 & 19,14 & 5,525 & 90,07 & & & \\
\hline \multirow{4}{*}{ Behavior } & 19-20 years & 33 & 17,36 & 4,014 & 77,00 & \multirow{4}{*}{8,828} & \multirow{4}{*}{,032 } & \multirow{4}{*}{$1<2,2>3$} \\
\hline & 21-22 years & 75 & 18,99 & 4,203 & 97,41 & & & \\
\hline & 23-24 years & 40 & 17,35 & 4,123 & 74,31 & & & \\
\hline & $24+$ years & 21 & 17,33 & 4,630 & 73,60 & & & \\
\hline \multirow{4}{*}{ Cultural Intelligence } & 19-20 years & 33 & 68,55 & 12,867 & 72,30 & \multirow{4}{*}{7,269} & \multirow{4}{*}{,064 } & \multirow{4}{*}{-} \\
\hline & 21-22 years & 75 & 74,36 & 13,452 & 96,09 & & & \\
\hline & 23-24 years & 40 & 69,68 & 14,571 & 78,80 & & & \\
\hline & $24+$ years & 21 & 69,71 & 13,062 & 77,14 & & & \\
\hline \multirow{4}{*}{$\begin{array}{c}\text { Academic Self- } \\
\text { efficacy }\end{array}$} & 19-20 years & 33 & 21,36 & 3,790 & 83,44 & \multirow{4}{*}{3,541} & \multirow{4}{*}{,315 } & \multirow{4}{*}{ - } \\
\hline & 21-22 years & 75 & 21,23 & 4,105 & 81,66 & & & \\
\hline & 23-24 years & 40 & 21,03 & 4,353 & 82,76 & & & \\
\hline & $24+$ years & 21 & 22,90 & 3,897 & 103,64 & & & \\
\hline
\end{tabular}


As shown in Table 3, When table is examined, it is seen that there is no statistically significant difference between cultural intelligence scale's metacognition, cognition, motivation levels and total cultural intelligence levels and academic self-efficacy levels of the participants according to their age groups $(p>0,05)$ and there is statistically significant difference between cultural intelligence scale's behavior levels of them according to their age groups $(\mathrm{p}<0,05)$. In cultural intelligence scale's behavior level, behavior level of the participants in age group 21-22 is significantly higher than behavior level of the participants in age group 19-20 and age group 23-24 $(\mathrm{p}<0,05)$.

Table-4.Comparison of Cultural Intelligence Scale Sub-Dimension Scores and Academic Self-Efficacy Scale Scores of the Participants According to Gender.

\begin{tabular}{|c|c|c|c|c|c|c|c|c|}
\hline Sub-dimension & Gender & $\mathbf{N}$ & $\mathbf{X}$ & Ss & Mean rank & Rank sum & $\overline{\mathbf{U}}$ & $\bar{p}$ \\
\hline \multirow{2}{*}{ Metacognition } & Female & 68 & 15,31 & 3,872 & 83,71 & 5692,5 & \multirow{2}{*}{3346,5} & \multirow{2}{*}{, 777} \\
\hline & Male & 101 & 15,70 & 3,261 & 85,87 & 8672,5 & & \\
\hline \multirow{2}{*}{ Cognition } & Female & 68 & 18,76 & 4,726 & 83,09 & 5650,0 & \multirow{2}{*}{3304,0} & \multirow{2}{*}{,676 } \\
\hline & Male & 101 & 19,01 & 4,840 & 86,29 & 8715,0 & & \\
\hline \multirow{2}{*}{ Motivation } & Female & 68 & 18,88 & 4,736 & 84,37 & 5737,0 & \multirow{2}{*}{3391,0} & \multirow{2}{*}{,890 } \\
\hline & Male & 101 & 19,09 & 4,589 & 85,43 & 8628,0 & & \\
\hline \multirow{2}{*}{ Behavior } & Female & 68 & 18,15 & 4,402 & 86,46 & 5879,5 & \multirow{2}{*}{3334,5} & \multirow{2}{*}{, 749} \\
\hline & Male & 101 & 18,03 & 4,156 & 84,01 & 8485,5 & & \\
\hline \multirow{2}{*}{$\begin{array}{c}\text { Cultural } \\
\text { Intelligence }\end{array}$} & Female & 68 & 71,10 & 14,994 & 84,82 & 5767,5 & \multirow{2}{*}{3421,5} & \multirow{2}{*}{,968 } \\
\hline & Male & 101 & 71,83 & 12,806 & 85,12 & 8597,5 & & \\
\hline \multirow{2}{*}{$\begin{array}{l}\text { Academic Self- } \\
\text { efficacy }\end{array}$} & Female & 68 & 20,93 & 3,861 & 78,93 & 5367,5 & \multirow{2}{*}{3021,5} & \multirow{2}{*}{, 184} \\
\hline & Male & 101 & 21,74 & 4,218 & 89,08 & 8997,5 & & \\
\hline
\end{tabular}

As shown in Table 4, When table is examined, it is seen that there is no statistically significant difference between cultural intelligence scale's metacognition, cognition, motivation, behavior levels and total cultural intelligence levels and academic self-efficacy levels of the participants according to their gender ( $p>0,05)$.

Table-5.Comparison of Cultural Intelligence Scale Sub-Dimension Scores and Academic Self-Efficacy Scale Scores of the Participants According to Department of Education.

\begin{tabular}{|c|c|c|c|c|c|c|c|c|}
\hline Sub-dimension & Department & $\mathbf{N}$ & $\mathbf{X}$ & Ss & Mean rank & $\mathbf{x}^{2}$ & $\mathbf{p}$ & $\begin{array}{c}\text { Difference } \\
\text { between groups }\end{array}$ \\
\hline \multirow{3}{*}{ Metacognition } & $\begin{array}{l}\text { Physical Education and } \\
\text { Sports Teaching }\end{array}$ & 91 & 15,73 & 3,873 & 90,81 & \multirow{3}{*}{8,412} & \multirow{3}{*}{, 015} & \multirow{3}{*}{$1>2,2<3$} \\
\hline & Coaching Education & 44 & 14,68 & 3,018 & 66,81 & & & \\
\hline & Sports Management & 34 & 16,18 & 2,928 & 93,00 & & & \\
\hline \multirow{3}{*}{ Cognition } & $\begin{array}{l}\text { Physical Education and } \\
\text { Sports Teaching }\end{array}$ & 91 & 19,05 & 5,201 & 88,17 & \multirow{3}{*}{,980 } & \multirow{3}{*}{,613 } & \multirow{3}{*}{-} \\
\hline & Coaching Education & 44 & 18,50 & 3,974 & 79,43 & & & \\
\hline & Sports Management & 34 & 19,06 & 4,664 & 83,72 & & & \\
\hline \multirow{3}{*}{ Motivation } & $\begin{array}{l}\text { Physical Education and } \\
\text { Sports Teaching }\end{array}$ & 91 & 18,98 & 4,604 & 84,26 & \multirow{3}{*}{2,768} & \multirow{3}{*}{, 251} & \multirow{3}{*}{-} \\
\hline & Coaching Education & 44 & 18,25 & 4,895 & 77,85 & & & \\
\hline & Sports Management & 34 & 20,06 & 4,299 & 96.22 & & & \\
\hline \multirow{3}{*}{ Behavior } & $\begin{array}{l}\text { Physical Education and } \\
\text { Sports Teaching }\end{array}$ & 91 & 18,37 & 4,451 & 89,36 & \multirow{3}{*}{2,533} & \multirow{3}{*}{,282 } & \multirow{3}{*}{-} \\
\hline & Coaching Education & 44 & 17,36 & 3,852 & 75,17 & & & \\
\hline & Sports Management & 34 & 18,21 & 4,169 & 86,06 & & & \\
\hline \multirow{3}{*}{$\begin{array}{c}\text { Cultural } \\
\text { Intelligence }\end{array}$} & $\begin{array}{l}\text { Physical Education and } \\
\text { Sports Teaching }\end{array}$ & 91 & 72,13 & 14,904 & 88,14 & \multirow{3}{*}{3,899} & \multirow{3}{*}{, 142} & \multirow{3}{*}{-} \\
\hline & Coaching Education & 44 & 68,80 & 11,820 & 72,78 & & & \\
\hline & Sports Management & 34 & 73,50 & 12,297 & 92,40 & & & \\
\hline \multirow{3}{*}{$\begin{array}{c}\text { Academic Self- } \\
\text { efficacy }\end{array}$} & $\begin{array}{l}\text { Physical Education and } \\
\text { Sports Teaching }\end{array}$ & 91 & 21,48 & 3,863 & 85,31 & \multirow{3}{*}{5,447} & \multirow{3}{*}{,066 } & \multirow{3}{*}{ - } \\
\hline & Coaching Education & 44 & 20,32 & 4,371 & 73,32 & & & \\
\hline & Sports Management & 34 & 22,65 & 4,029 & 99,28 & & & \\
\hline
\end{tabular}

As shown in Table 5, When table is examined, it is seen that there is no statistically significant difference between cultural intelligence scale's cognition, motivation, behavior levels and total cultural intelligence levels and academic self-efficacy levels of participants according to their department of education ( $p>0,05)$ and there is statistically significant difference between cultural intelligence scale's metacognition levels of them according to their department of education $(\mathrm{p}<0,05)$. In cultural intelligence scale's metacognition level, metacognition level of the participants studying in department of physical education and sports teaching and department of sports management is significantly higher than metacognition level of the participants studying in department of coaching education $(\mathrm{p}<0,05)$. 
Table-6. Comparison of Cultural Intelligence Scale Sub-Dimension Scores and Academic Self-Efficacy Scale Scores of the Participants According to Year of Education.

\begin{tabular}{|c|c|c|c|c|c|c|c|c|}
\hline Sub-dimension & Year & $\mathbf{N}$ & $\mathbf{X}$ & Ss & Mean rank & $x^{2}$ & p & Difference between groups \\
\hline \multirow{4}{*}{ Metacognition } & 1st year & 58 & 16,07 & 3,665 & 95,70 & \multirow{4}{*}{4,594} & \multirow{4}{*}{,204 } & \multirow{4}{*}{-} \\
\hline & 2nd year & 27 & 15,07 & 3,647 & 78,17 & & & \\
\hline & 3rd year & 57 & 15,23 & 3,480 & 77,89 & & & \\
\hline & 4th year & 27 & 15,56 & 3,142 & 83,87 & & & \\
\hline \multirow{4}{*}{ Cognition } & 1 st year & 58 & 18,40 & 4,870 & 78,13 & \multirow{4}{*}{1,891} & \multirow{4}{*}{, 595} & \multirow{4}{*}{ - } \\
\hline & 2nd year & 27 & 19,11 & 5,679 & 87,78 & & & \\
\hline & 3rd year & 57 & 18,98 & 4,565 & 87,53 & & & \\
\hline & 4th year & 27 & 19,67 & 4,169 & 91,65 & & & \\
\hline \multirow{4}{*}{ Motivation } & 1st year & 58 & 19,47 & 5,175 & 93,33 & \multirow{4}{*}{3,626} & \multirow{4}{*}{, 305} & \multirow{4}{*}{-} \\
\hline & 2nd year & 27 & 18,93 & 3,772 & 81,24 & & & \\
\hline & 3rd year & 57 & 18,33 & 4,703 & 76,72 & & & \\
\hline & 4th year & 27 & 19,52 & 4,070 & 88,35 & & & \\
\hline \multirow{4}{*}{ Behavior } & 1st year & 58 & 17,52 & 4,943 & 81,44 & \multirow{4}{*}{1,150} & \multirow{4}{*}{,765 } & \multirow{4}{*}{ - } \\
\hline & 2nd year & 27 & 17,93 & 3,842 & 84,22 & & & \\
\hline & 3rd year & 57 & 18,63 & 3,890 & 90,48 & & & \\
\hline & 4th year & 27 & 18,26 & 3,748 & 81,85 & & & \\
\hline \multirow{4}{*}{ Cultural Intelligence } & 1st year & 58 & 71,45 & 15,838 & 87,85 & \multirow{4}{*}{,708 } & \multirow{4}{*}{,871 } & \multirow{4}{*}{-} \\
\hline & 2nd year & 27 & 71,04 & 13,435 & 83,61 & & & \\
\hline & 3rd year & 57 & 71,18 & 12,482 & 81,13 & & & \\
\hline & 4th year & 27 & 73,00 & 11,923 & 88.43 & & & \\
\hline \multirow{4}{*}{ Academic Self-efficacy } & 1st year & 58 & 22,69 & 4,398 & 101,14 & \multirow{4}{*}{10,857} & \multirow{4}{*}{,013 } & \multirow{4}{*}{$1>3$} \\
\hline & 2nd year & 27 & 21,30 & 3,930 & 81,52 & & & \\
\hline & 3rd year & 57 & 20,23 & 4,022 & 71,68 & & & \\
\hline & 4th year & 27 & 21,30 & 2,906 & 81,94 & & & \\
\hline
\end{tabular}

As shown in Table 6, When table is examined, it is seen that there is no statistically significant difference between cultural intelligence scale's metacognition, cognition, motivation, behavior levels and total cultural intelligence levels of participants according to their year of education ( $>>0,05)$ and there is statistically significant difference between academic self-efficacy levels of them according to their year of education $(p<0,05)$. Academic self-efficacy level of the participants studying in 1st year is significantly higher than the participants studying in 3rd year $(\mathrm{p}<0,05)$.

Table-7. Study on Relationship Between Cultural Intelligence Levels and Academic Self-Efficacy of the Participants

\begin{tabular}{|c|c|c|c|c|c|c|}
\hline \multirow{2}{*}{\multicolumn{2}{|c|}{ Variables }} & \multicolumn{5}{|c|}{ Cultural Intelligence scale sub-dimensions } \\
\hline & & \multirow{2}{*}{$\frac{\text { Metacognition }}{, 256}$} & \multirow{2}{*}{$\begin{array}{c}\text { Cognition } \\
, 140\end{array}$} & \multirow{2}{*}{$\frac{\text { Motivation }}{, 318}$} & \multirow{2}{*}{$\frac{\text { Behavior }}{, 236}$} & \multirow{2}{*}{$\begin{array}{c}\text { Cultural Intelligence } \\
, 324\end{array}$} \\
\hline \multirow{3}{*}{$\begin{array}{c}\text { Academic } \\
\text { Self-efficacy }\end{array}$} & $\mathrm{r}$ & & & & & \\
\hline & $\mathrm{p}$ & ,001 & ,070 & ,000 & ,002 & ,000 \\
\hline & $\mathrm{N}$ & 169 & 169 & 169 & 169 & , 169 \\
\hline
\end{tabular}

As shown in Table 7, When table is examined, it is seen that there is a statistically significant and positive relationship below medium level between academic self-efficacy and cultural intelligence metacognition, motivation, behavior levels and total cultural intelligence levels of the participants $(p<0,05)$ and there is no statistically significant relationship between cultural intelligence cognition levels and academic self-efficacy levels $(\mathrm{p}>0,05)$.

\section{Discussion and Conclusion}

Following results have been obtained in the study conducted in order to examine cultural intelligence levels and academic self-efficacy of university students according to different variables and to reveal relationship between them;

It has been seen that participants are in age group 19 and $24+$ and ratio of females and males is almost fiftyfifty. $53,8 \%$ of the participants study in department of physical education and sports teaching, $26 \%$ of them study in department of coaching education and $20,1 \%$ of them study in department of sports management, $34,3 \%$ of them are in their 1 st year, $16 \%$ are in 2 nd year, $33,7 \%$ are in 3 rd year and $16 \%$ are in 4 th year. While $40,8 \%$ of the participants accommodate in dormitory, $32 \%$ of them accommodate in their families' houses and $27,2 \%$ accommodate in student house. It has been concluded that $62,1 \%$ of the participants are interested in sports as an amateur while $26 \%$ are interested in sports professionally and $11,8 \%$ of them are engaged in sports as a referee. It has been determined that participants get high scores in metacognition dimension of cultural intelligence scale subdimensions, they get score above medium level, close to high level in motivation and behavior sub-dimensions, they get medium level score in cognition dimension, they get score above medium level in whole scale and they get medium level score in academic self-efficacy scale.

When comparison of cultural intelligence scale sub-dimension scores and academic self-efficacy scale scores of participants according to age groups has been examined, it has been determined that there is no statistically significant difference between cultural intelligence scale's metacognition, cognition, motivation levels and total cultural intelligence levels and academic self-efficacy levels of participants and there is statistically significant difference between cultural intelligence scale's behavior levels of them according to their age groups. In cultural intelligence scale's behavior level, it has been determined that behavior level of the participants in age group 21-22 is significantly higher than behavior level of the participants in age group 19-20 and age group 23-24 Table 3. When relevant literature was examined, Demir (2015) found in his study on relationship between cultural intelligence and burnout that there was no relationship between cultural intelligence levels of the employees 
according to age variable. In his study named "Effect of cultural intelligence on acculturation of foreign students", Konate (2018) determined that cultural intelligence levels of the students did not differ significantly according to age. In academic self-efficacy, Topçuoğlu (2018) determined in his study named "Examination of life quality and academic self-efficacy levels of students studying in department of physical education and sports teaching" that academic self-efficacy of the participants did not differ according to gender variable. It has been seen that there are findings that are not similar with our study findings. It is thought that these differences are caused by different age categories of study groups. At the same time, it is possible to say that geography where they live, affects cultural intelligence and academic self-efficacy levels.

When comparison of cultural intelligence scale sub-dimension scores and academic self-efficacy scale scores of participants according to gender is examined, it is seen that there is no statistically significant difference between cultural intelligence scale's metacognition, cognition, motivation, behavior levels and total cultural intelligence levels and academic self-efficacy levels of participants Table 4. Demir (2015) found in his study on relationship between cultural intelligence and burnout that there was no relationship between cultural intelligence levels of the employees according to gender variable. Topçuoğlu (2018) determined in his study named "Examination of life quality and academic self-efficacy levels of students studying in department of physical education and sports teaching" that academic self-efficacy of the participants did not differ according to gender variable. In his study named "Effect of cultural intelligence on acculturation of foreign students", Konate (2018) determined that cognitive cultural intelligence in cultural intelligence levels of the students differed significantly according to gender. According to his findings, he found that males' cognitive intelligence scores were higher when compared to female students.

When comparison of cultural intelligence scale sub-dimension scores and academic self-efficacy scale scores of participants according to their department of education is examined, it is seen that there is no statistically significant difference between cultural intelligence scale's cognition, motivation, behavior levels and total cultural intelligence levels and academic self-efficacy levels of participants and there is statistically significant difference between cultural intelligence scale's metacognition levels of them according to their department of education. In cultural intelligence scale's metacognition level, it has been found that metacognition level of the participants studying in department of physical education and sports teaching and department of sports management is significantly higher than metacognition level of the participants studying in department of coaching education Table 5. Metacognition dimension of cultural intelligence is focused on ability to process information (Earley and Ang, 2003) and it is about awareness of cultural knowledge that an individual uses during intercultural interaction and whether he/she has control over this knowledge (Ang and Dyne, 2008). Therefore, from this point of view, it is possible to say that physical education and sports teaching students and sports management students are more skilled than coaching education students in terms of information processing and use of this information by being aware of cultural knowledge and at the same time, having better control over this information, their communication with different cultures, planning and adaptation. Regarding academic self-efficacy, we can say that departments of students do not affect their academic self-efficacy.

When comparison of cultural intelligence scale sub-dimension scores and academic self-efficacy scale scores of participants according to their year of education is examined, it is seen that there is no statistically significant difference between cultural intelligence scale's metacognition, cognition, motivation, behavior levels and total cultural intelligence levels of participants and there is statistically significant difference between academic selfefficacy levels of them according to their year of education. Academic self-efficacy level of the participants studying in 1 st year is significantly higher than the participants studying in 3rd year Table 6. As a result of his research about students, Eryenen (2008) determined that academic self-efficacy of students differed according to their year of education. In another study, Topçuoğlu (2018) determined in his study named "Examination of life quality and academic self-efficacy levels of students studying in department of physical education and sports teaching" that academic self-efficacy of the participants differed significantly according to year of education variable. According to study findings; it was concluded that academic self-efficacy of students in 1st year was significantly higher than students in 2nd year. Therefore, this is similar with our study findings. It was seen that study conducted by Küçük and Öncü (2013) did not differ significantly in terms of year of education variable. In other words, when year of education differences were examined, it was seen that participants' academic self-efficacy decreased as their year of education increased. It is thought that this situation is due to the fact that students give importance to the lessons more in 1st year and they are more concerned about examinations. In addition, it is possible to say that academic self-efficacy of students who are in upper classes decreases because of their concerns for the future or graduation excitement.

When relationship between cultural intelligence levels and academic self-efficacy of participants was examined, it was concluded that there was a statistically significant and positive relationship below medium level between academic self-efficacy and cultural intelligence metacognition, motivation, behavior levels and total cultural intelligence levels and there was no statistically significant relationship between cultural intelligence cognition levels and academic self-efficacy levels Table 7. When characteristics of sub-dimensions of cultural intelligence scale are considered, it is thought that cultural intelligence metacognition (Awareness of cultural knowledge that an individual uses during intercultural interaction and situations whether he/she has control over this knowledge) affect the participants' perceptions of academic self-efficacy positively.

Motivation dimension of cultural intelligence (is about an individual's willingness to interact with people from different cultures and to learn something about intercultural situations) (Ang et al., 2004; Ang et al., 2006; Ng and Earley, 2006; Ang and Dyne, 2008; $\mathrm{Ng}$ et al., 2009) it is seen that students with such characteristics have high academic self-efficacy perception. Characteristics of another dimension of cultural intelligence which is behavior dimension (Individuals' ability to exhibit appropriate verbal or non-verbal behaviors when they meet people having different cultural backgrounds), reveal relevant situation about academic self-efficacy. It was seen that characteristics of cognition dimension of cultural intelligence (It includes knowledge about other cultures which is acquired by an individual with the help of daily experiences or formal education) was not related to academic selfefficacy. 
It is possible to say that students who have characteristics of cultural intelligence and who act in accordance with these characteristics, exhibit a situation related to academic self-efficacy.

\section{References}

Aman, F., 2012. Ows Bronislaw Malinowski's cultural theory. Uludag University Faculty of Theology Journal, 2(1): 135-151.

Ang, S. and V.L. Dyne, 2008. Conceptualization of cultural intelligence: Definition, distinctiveness, and nomological network. In S. Ang, \& L. Van Dyne, (Ed.), Handbook on cultural intelligence: Theory, measurement and applications. Armonk, NY: M.E. Sharpe. pp: 3-15.

Ang, S., V.L. Dyne and C. Koh, 2006. Personality correlates of the four-factor model of cultural intelligence. Group \& Organization Management, 31(1): 100-123.Available at: https://doi.org/10.1177/1059601105275267.

Ang, S., V.L. Dyne, N.K. Yee and C. Koh, 2004. The measurement of cultural intelligence. Paper Presented at the Annual Meeting of the Academy of Management, New Orleans, LA.

Ang, S., L. Van Dyne, C. Koh, K.Y. Ng, K.J. Templer, C. Tay and N.A. Chandrasekar, 2007. Cultural intelligence: Its measurement and effects on cultural judgment and decision making, cultural adaptation and task performance. Management and Organization Review, 3(3): 335-371.Available at: https://doi.org/10.1111/j.1740-8784.2007.00082.x.

Bandura, A., 1997. Self-efficacy: The exercise of control. New York: Freeman.

Creswell, J.W., 2013. Research design: Qualitative, quantitative and mixed method approaches. (Trans. Selcuk Besir Demir). Ankara: Educated Book.

Demir, G., 2015. The relationship between cultural intelligence and burnout: A research in accommodation enterprises. Balikesir: Balıkesir University. Social Sciences Institute.

Earley, P.C. and S. Ang, 2003. Cultural intelligence: Individual interactions across cultures. Palo Alto, CA: Stanford University Press.

Earley, P.C. and E. Mosakowski, 2004. Cultural intelligence. Harvard Business Review, 82(10): 139-146.

Elias, S.M. and R.J. Loomis, 2002. Utilizing need for cognition and perceived self-efficacy to predict academic performance 1. Journal of Applied Social Psychology, 32(8): 1687-1702.Available at: https://doi.org/10.1111/j.1559-1816.2002.tbo2770.x.

Erkus, A., 2013. Scientific research process for behavioral sciences. Ankara: Seçkin Yayın.

Eroğlu, F., 2007. Behavioral sciences. İstanbul: Beta Broadcasting.

Eryenen, G., 2008. The relationship between the prospective teachers' target orientation, academic and teaching proficiency and their role in predicting the academic achievement. Master Thesis, Istanbul University Institute of Social Sciences, Department of Psychological Services in Education, Istanbul.

Gibson, C.B. and R. Dibble, 2008. Culture inside and out: Developing a collaboration's capacity to externally adjust. S. Ang, \& L. Van Dyne (Dü), Handbook of cultural intelligence: Theory, measurement, and applications. Armonk, NY: M. E. Sharpe. pp: 221-240.

House, J.D., 1992. The relationship between academic self-concept, achievement-related expectancies, and college attrition. Journal of College Student Development, 33(1): 5-10.

Jerusalem, M., 2002. Theroretischerteil - introduction I. Zeitschrift Für-pädagogik. Berlin: Beltz publications. pp: 8-12.

Jerusalem, M. and R. Schwarzer, 1981. Questionnaire for recording self-efficacy, scales of well-being and personality. In R. Schwarzer (Ed.). (Research Report No. 5). Berlin: Free University, Institute of Psychology.

Karasar, N., 2012. Scientific research method. Ankara: Nobel Academic Publishing.

Konate, T., 2018. The effect of cultural intelligence on the cultural coherence of foreign students. Master's Thesis. Akdeniz University Institute of Social Sciences Antalya.

Korkmaz, I., 2004. Social learning theory. Binnur Yeşilyaprak (Ed.), Psychology of Development and Learning (6th Edn.,). Ankara: Pegem Publishing. pp: 197-220.

Küçük, K.S. and E. Öncü, 2013. Metacognitive learning strategies and academic self-efficacy of physical education and sports college students. 6. National Sports Sciences Student Congress, 17-19 May/Turkey.

Lent, R.W., S.D. Brown and K.C. Larkin, 1984. Relation of self-efficacy expectations to academic achievement and persistence. Journal of Counseling Psychology, 31 (3): 356-362.Available at: https://doi.org/10.1037//0022-0167.3 1.3.356.

$\mathrm{Ng}$, K.-Y. and P.C. Earley, 2006. Culture+ intelligence: Old constructs, new frontiers. Group \& Organization Management, 31(1): 419.Available at: https://doi.org/10.1177/1059601105275251.

Ng, K.-Y., L. Van Dyne and S. Ang, 2009. From experience to experiential learning: Cultural intelligence as a learning capability for global leader development. Academy of Management Learning \& Education, 8(4): 511-526.Available at: https://doi.org/10.5465/amle.8.4.zqr511.

Pajares, F., 1997. Current directions in self-efficacy research. In M. Maehr ve P.R. Pintrich (Eds.), Advances in motivation and achievement. Greenwich, CT: JAI Press. pp: 1-49.

Schunk, D., 1981. Modeling and attributional effects on children's achievemednt: A self-efficacy analysis. Journal of Educational Psychology, 73(1): 93-105.Available at: https://doi.org/10.1037//0022-0663.73.1.93.

Schunk, D.H., 1982. Effects of effort attributional feedback on children's perceived self-efficacy and achievement. Journal of Educational Psychology, 74(4): 548-556.Available at: https://doi.org/10.1037//o022-0663.74.4.548.

Solberg, V.S., K. O'Brien, P. Villareal, R. Kennel and B. Davis, 1993. Self-efficacy and hispanic college students: Validation of the college selfefficacy instrument. Hispanic Journal of Behavioral Sciences, 15(1): 80-95.Available at: https://doi.org/10.1177/07399863930151004.

Thomas, D. and K. Inkson, 2004. Cultural intelligence: People skills for global business. San Francisco, CA: Berrett-Koehler.

Topçuoğlu, N., 2018. Investigation of university life quality and academic self-efficacy of physical education and sports teaching students. Master Thesis. Ağrı İbrahim Çeçen University Institute of Social Sciences. Pain.

Uzel, A., 2009. Determination of self-efficacy perceptions and learning needs of foreign language teachers and school administrators. Master's thesis, Yeditepe University Institute of Social Sciences, Istanbul.

Vrugt, A.J., M.P. Langereis and J. Hoogstraten, 1997. Academic self-efficacy and malleability of relevant capabilities as predictors of exam performance. The Journal of Experimental Education, 66(1): 61-72.Available at: https://doi.org/10.1080/00220979709601395.

Wood, R.E. and E.A. Locke, 1987. The relation of self-efficacy and grade goals to academic performance. Educational and Psychological Measurement, 47(4): 1013-1024.Available at: https://doi.org/10.1177/0013164487474017.

Wu, Z.X., 2012. A computational model of open and extensible cultural intelligence. Unpublished PhD Thesis, University of Quebec in Montreal, Cognitive Computing Department, Canada.

Yeşil, S., 2009. Management of cultural differences and an alternative strategy: Cultural intelligence. KMU Journal of Economics and Administrative Sciences, 11(16): 100-131.

Yılmaz, M., D. Gürçay and G. Ekici, 2007. Adaptation of academic self-efficacy scale to Turkish. Hacettepe University Faculty of Education Journal, 33(33): 253-259.

Zimmerman, B.J., 1995. Self-efficacy and educational development. In A. Bandura (Ed.), Self-efficacy in changing societies. New York: Cambridge University Press. pp: 202-231. 